\title{
Visual autokinesis as a function of the amount of "possible" movement
}

W. F. DA VES, MARIA KELNHOFER, and C. L. HOLLAND, Georgia State College, Atlanta, Ga. 30303

Reports of autokinetic movement were obtained from 10 male and 10 female $\mathrm{Ss}$ when the light was remembered as appearing in a large (15 in. square) window or in a small ( 5 in. square) window. The effect of exposure duration (10 sec vs $20 \mathrm{sec})$, trial blocks, and sex of $S$ were also varied in the 2 by 2 by 2 by Ss design. More movement was reported for the large window $(p<.025)$, the 20-sec duration $(p<.001)$, and the first trial block $(p<.025)$. No other effects were significant. The results were discussed in terms of a cognitive organization imposed upon the inherently ambiguous perceptual situation.

The autokinetic effect has been shown to be sensitive to a large number of variables. Recent studies have related it to sensory deprivation (Doane, Mahatoo, Heron, \& Scott, 1959), social deprivation (Walters \& Quinn, 1961), "directional meaning" (Toch, 1962), the influence of other people in a social situation (Whittaker, 1964), instructions by E (Cautela \& Vitro, 1964), repeated exposures and massed vs distributed practice (Farrow, Santos, Haines, \& Solley, 1965), and success vs failure experiences (Worthy \& Kahn, 1967). In addition, there is a large body of literature ranging from the psychophysiological basis for the phenomenon (e.g., Matin \& MacKinnon, 1964; Gregory \& Zangwill, 1963) to the extent of its influence by social psychological factors (e.g., summarized by Sherif \& Sherif, 1956).

It is obvious from perusal of this literature that very little has been accomplished by way of systematizing the exceedingly varied effects one obtains with this phenomenon. While concepts involving the establishment of social norms have been advanced to account for much of the work (e.g., Sherif, 1956), it is possible that a more general theoretical framework may account for a wider variety of the effects. The point of departure for the present investigation is the possiblity that many of the findings might be understood in terms of a general tendency for Ss to establish a frame of reference, based upon any and all relevant information available, from which to judge stimuli (Helson, 1964). Such information might come from reports of other Ss in the situation, from what the $E$ has told $S$ about it (intended or otherwise), or from generalization from previous experiences with similar situations (Hoffman, Swander, \& Rohrer, 1953).

The present experiment is an attempt to manipulate S's frame of reference in the autokinetic situation by giving him indirect cognitive information about how much movement he should report. The cognitive information is varied by changing the physical context in which the autokinetic light (AKL) is viewed. Specifically, it was predicted that a naive $S$ would "know" that more movement could occur if he remembered the opening in which he saw the AKL as having been large rather than small, and that his report would be consistent with this knowledge. In other words, the remembered size of the opening would establish a frame of reference for the report of movement on that trial.

\section{SUBJECTS}

Subjects were 10 male and 10 female volunteers from introductory psychology classes, tested at the beginning of the Fall Quarter, 1968. Every effort was made to enlist Ss before the autokinetic effect was discussed in class, and, as well as could be determined, all Ss were naive as to the effect and purpose of the experiment.

\section{APPARATUS}

Each AKL consisted of a spot of light $1 / 16$ in. in diam, obtained by masking a $2 \times 2$ in. General Electric electroluminescent lamp, which produced nominally white light. Two AKLs were used and were mounted inside a large orange-colored box, 33 in. wide, 29.25 in. high, and 13.25 in. deep. A large (15 in. square) and a small ( 5 in. square) opening was cut in the side of the box facing $S$, and a translucent screen of Mylar drafting paper was mounted behind each opening. The centers of the openings were approximately $6 \mathrm{ft}$. from S's chair, 16 in. or $12.7 \mathrm{deg}$ apart, and aligned with S's horizontal meridian. One AKL was centered behind each screen. Centered above each opening was an instruction light (IL), which consisted of a Christmas tree lamp, shielded from S's direct

Table 1

Mean Amount of Autokinetic Movement Reported (Inches) as a Function of Stimulus Duration, Window Size, Trial Blocks and Sex

\begin{tabular}{|c|c|c|c|c|c|c|c|c|}
\hline \multirow[b]{4}{*}{$\underline{\text { Sex }}$} & \multicolumn{8}{|c|}{ Condition } \\
\hline & \multicolumn{4}{|c|}{$10 \mathrm{Sec}$} & \multicolumn{4}{|c|}{$20 \mathrm{Sec}$} \\
\hline & \multicolumn{2}{|c|}{ Small Window } & \multicolumn{2}{|c|}{ Large Window } & \multicolumn{2}{|c|}{ Small Window } & \multicolumn{2}{|c|}{ Large Window } \\
\hline & Blk 1 & Blk 2 & Blk 1 & Blk 2 & Bik 1 & Blk 2 & Blk 1 & Blk 2 \\
\hline Male & 12.0 & 8.9 & 14.2 & 12.0 & 19.9 & 15.6 & 23.5 & 18.1 \\
\hline Female & 9.1 & 7.8 & 9.1 & 9.7 & 12.8 & 11.3 & 16.2 & 15.3 \\
\hline
\end{tabular}
parallel with the AKLs, so that when an AKL was turned on, the motor began running audibly. The ILs and the AKLs were controlled by a Hunter Model 1514 timer. S and the AKL apparatus were situated in a light-tight room with black walls. E was in an adjacent room and communicated with $S$ by means of an intercom.

\section{PROCEDURE}

Each $S$ was told that the experiment was a test of two different screens. On each trial, he would be informed by the appropriate IL as to which screen he was viewing. He was told that, following the extinction of the IL, a small white light would appear, and that he should observe the light and, as soon as it was extinguished, report aloud how many inches it moved.

On each trial, the IL was presented for $0.5 \mathrm{sec}$, followed $1 \mathrm{sec}$ later by the AKL which lasted either 10 or $20 \mathrm{sec}$. The design thus consists of two window sizes, combined with two AKL durations, yielding four conditions. Eight trials per condition were run, ordered according to two tandem 4 by 4 Latin squares. This tandem arrangement permitted the assessment of time (two trial blocks) in the experimental situation.

Following the 32 trials of the experiment, each $S$ was asked to describe what he thought was the purpose of the experiment. RESULTS

First of all, no $S$ indicated that he knew the purpose of the experiment, stating only what $E$ had told them previously. With regard to the amount of movement reported, the experimental design permitted the assessment of four effects: window size, AKL duration, trial blocks, and sex. The mean number of inches of movement reported under the 16 combinations of these conditions is shown in Table 1. Analysis of variance of these data indicated none of the interactions, when tested against the appropriate $\mathbf{S}$ interaction, to be significant. Although males appeared to report more movement than females, this difference was not significant $[F(1 / 18)=1.54]$. The three

view by a shade made of black construction paper. The IL, when switched on, illuminated the AKL screen below it, thus informing $S$ which screen he was to view on the next trial. A synchronous motor was mounted inside the box and was wired in

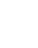


Table 2

Mean Inches of Movement Reported and Results of Analysis of Variance for the Three Significant Main Effects

\begin{tabular}{llll}
\hline & \multicolumn{3}{c}{ Significant } \\
Variable & Condition & Mean & F $^{1}$ \\
\hline Window & Large & 14.8 & \\
Size & Small & 12.2 & $7.88^{*}$ \\
AKL & $10 \mathrm{sec}$ & 10.4 & \\
Duration & $20 \mathrm{sec}$ & 16.6 & $32.40^{* *}$ \\
Trial & 1 & 14.6 & \\
Blocks & 2 & 12.3 & $6.41^{*}$ \\
\hline
\end{tabular}

$1 d f=1 / 18$ for all comparisons

$* p<.025 ; * * p<.001$

other main effects, however, were significant (see Table 2). More movement was reported for the larger window, the $20-\sec$ AKL duration, and the first trial block.

\section{DISCUSSION}

The results of this study indicate that Ss do tend to make larger judgments when the AKL is presented in a large rather than a small window. The question, however, may arise as to whether this result could be due to an afterimage produced by the instruction light when it illuminated the AKL screen. Such an afterimage might provide an excellent quasiexternal frame of reference for judgment of the AKL. However, E was unable to observe any such afterimage when he tested himself under the experimental conditions. Furthermore, failure to find a significant interaction of window size with either of the temporal variables (AKL duration and trial blocks) or a triple interaction involving the three variables (all Fs were less than 1.0) tends to render the afterimage interpretation less plausible, since the afterimage would be expected to fade with time during a trial (AKL duration) and to increase in intensity with time in the dark (trial blocks).

The present results lend support to the idea that the amount of movement reported in the autokinetic situation is at least partly determined by the cognitive aspects of the situation, i.e., what S "knows" is likely to happen. If this interpretation can be shown to have general value in future experiments using a variety of means of giving $S$ information about the AKL, then it would perhaps be feasible to integrate certain of the findings with this phenomenon, particularly those in which the effect of various social variables has been reported. Thus, information about the light may come from other Ss in the situation (Sherif \& Sherif, 1956), the E (Cautela \& Vitro, 1964), generalization from an experience with real movement under similar conditions (Hoffman, Swander, \& Rohrer, 1953), or S's own cognitive assessment of the physical possibilities in the situation (the present experiment).
In other words, on the basis of whatever information is available, $S$ develops a frame of reference for interpreting the physiologically determined experience of instability in the AKL, which then operates to affect his judgments, i.e., his relation of the experience to the external scale (e.g., inches) imposed by the $E$.

Future research might explore either the importance of different sources of information (e.g., cognitive vs social) in the establishment of frames of reference, or perhaps, the range of sources of cognitive information which can affect $S$ 's judgment.

\section{REFERENCES}

CAUTELA, J., \& VITRO, F. The effect of instruction on the appearance of the autokinetic effect. Journal of Psychology, 1964, 58, 85-88.

DOANE, B. K., MAHATOO, W., HERON, W., \& SCOTT, T. H. Changes in perceptual function after isolation. Canadian Journal of Psy chology, $1959,13,210-219$.

FARROW, B. J, SANTOS, J, F. HAINES, J. R, \& SOLLEY, C. M. Influence of repeated experience on latency and extent of autokinetic movement. Perceptual \& Motor Skills, 1965, 20 1113-1120.

GREGORY, R. L., \& ZANGWILL, O. L. The origin of the autokinetic effect. Quarterly Journal of Experimental Psychology, 1963, 15, 252-261.

HELSON, H. Adaptation level theory. New York: Harper \& Row, 1964.

HOFFMAN, E. L., SWANDER, D. V., BARON, S, H., \& ROHER, J. H. Generalization and exposure time as related to autokinetic movement. Journal of Experimental Psychology, 1953, 46, 171-177.

MATIN, L., \& MacKINNON, G. E. Autokinetic movement: Selective manipulation of directional components by image stabilization. Science, 1964, 143, 147-148.

SHERIF, M., \& SHERIF, C. W. An outline of social psychology. New York: Harper \& Row, 1956.

TOCH, H. H. The effect of "meaning" on the autokinetic illusion. American Joumal of Psychology, 1962, 75, 605-611.

WALTERS, R. H., \& QUINN, M. J. A comparison of the effects of social deprivation and sensory deprivation on autokinetic judgments. Unpublished manuscript, 1961. Cited in J. F. Corso, The experimental psychology of sensory behavior. New York: Holt, Rinehart \& Win ston, 1967. P. 558.

WHITTAKER, J. O. Parameters of social influence in the autokinetic situation. Sociometry, 1964, 27, 88-95.

WORTHY, M., \& KAHN, G. The effects of situational and personal variables on vertical autokinesis. Psychonomic Science, 1968, 11, 144.

\section{Mediational construction vs. mediational perception in paired-associate learning}

LEROY H. PELTON, State University of New York at Albany, Albany, N.Y. 12203

Noun paired associates were presented for one study trial under instructions to construct sentences containing the pairs (construction), to listen to and to repeat ready-made sentences containing the pairs (perception), or merely to read the pairs aloud (control). Recall was greater for construction than for perception. Recall in the construction group was not significantly greater than in the control group, and it was conjectured that this might be due to spontaneous mediational construction in the latter group. The hypothesis that the construction of mediation by the $S$ himself is more effective than the perception of a ready-made mediational link was supported.

There is evidence that instructions to mediate facilitate paired-associate (PA) learning (Paivio \& Yuille, 1967; Yarmey \& Csapo, 1968; Yuille \& Paivio, 1968). There is also evidence that the perception of a ready-made mediational link facilitates $P A$ learning (Jensen \& Rohwer, 1963). The phenomenon of mediation raises important questions as to the nature of the thought process and the role of relations in learning. What is it about mediational links that facilitates learning? New facts need to be discovered to further our understanding of this organizational process.

It can be asked whether or not the construction of the relation by the $S$ himself is itself an important factor, or if the mere perception of a relation is just as adequate as construction. Bühler (Humphrey, 1963, p. 63) claimed that when one is induced to actively think, memory is much improved. He showed that proverbs are remembered excellently, and he theorized that the proverbs made his Ss think, and that the thought is remembered where sheer sensory material would be forgotten. On this basis, it was hypothesized here that the construction of a relation by the $S$ would be superior to the perception of a ready-made mediational link.

This hypothesis has recently been tested, but not supported, in an experiment by Lieberman, Walters, \& Cox (1968). They presented 42 pairs once at $10-\mathrm{sec}$ intervals. 